\title{
Identifying of Homoneura (Diptera: Lauxaniidae) females by means of geometric morphometrics
}

Marek Semelbauer

Identifying of Homoneura (Diptera: Lauxaniidae) females by means of geometric morphometrics. Acta Mus. Siles. Sci. Natur., 66: 75-86, 2017.

\begin{abstract}
The females of the European species Homoneura consobrina, H. patelliformis and H. thalhammeri are not easy to discern. A possible method of identifying females is to apply geometric morphometrics to the wing shape, when we expect females of certain species to have wing shape more similar to conspecific males, than to other species. For this purpose, 94 specimens of the three species were collected mainly by means of Malaise trap in western and central Slovakia and Montenegro. The combination of morphological and distribution data allowed for the females to be divided into three groups. In next step, wings of both males and females were digitized, aligned by Generalized Procrustes Analysis and analyzed via multivariate methods (principal component analysis, multivariate analysis of variance, linear discriminant analysis). Results of the analysis clearly suggest that females with large and convex 8th sternite belong to $H$. patelliformis, while females with reduced 8th sternite belong to either $H$. thalhammeri or $H$. consobrina.
\end{abstract}

Key words: Slovakia, female terminalia, morphology, Homoneura consobrina, H. patelliformis, H. thalhammeri

\section{Introduction}

Females of many insect species are difficult or even impossible to identify to species. A natural explanation for this, is that the females are morphologically uniform. Alternatively, females can be morphologically distinct, but this was for various reasons overlooked.

Three species of Homoneura van der Wulp, 1891 are an example of such a situation: $H$. consobrina (Zetterstedt, 1847), H. patelliformis (Becker, 1895) and H. thalhammeri Papp, 1978. They are widely distributed throughout Europe (Shatalkin 2000) and are habitually very similar, being small stocky flies (Fig. 1) with hyaline wings, 6 rows of acrostichal setae and three pairs of dorsocentral setae. At least two other western European species are related to the group: H. ericpoli Carles-Tolrá 1993 and H. chelis Carles-Tolrá 1996 (Carles-Tolrá 1993, Carles-Tolrá 1996), as is suggested by their male genitalia. Their biology is little known. Merz (2002) mentions that $H$. patelliformis is occasionally common, occurring also at ruderal sites. On the other hand, the latter two species occur much more rarely, at warm or xerotherm sites and with the presence of bushes or forest edges.

$H$. consobrina and $H$. thalhammeri have male genitalia very similar in shape (see Figs 34 in Semelbauer 2015), what possibly led Merz (2002) to question the delimitation of the two species. It is true that Papp (1978) in his description of $H$. thalhammeri does not discuss delimitation of the two species. On the other hand, $H$. patelliformis strikingly differs from the latter pair in male genitalia (see Figs in Semelbauer \& Vidlička 2015). The phylogenetic analysis of DNA sequences (Semelbauer 2016) suggests that $H$. patelliformis is not closely related to $H$. patelliformis.

In all three species, the females are barely identifiable using the available keys. According to Papp (1979) females of H. patelliformis and H. thalhammeri are not discernible. Shatalkin (2000) uses the length of aristal setae to discern the two species (longer than thickness of basal part of arista for $H$. thalhammeri, not longer for $H$. consobrina). This difference is slight and according to the author's experience males of $H$. thalhammeri and $H$. patelliformis barely differ in this character. As a result, females of the two species are difficult to recognise. 
According to Papp (1979) females of $H$. consobrina have a short 7th sternit, which is sparsely covered in setae, while female $H$. patelliformis and $H$. thalhammeri should have a long 7th sternit covered in dense and long setae. Shatalkin (2000) adds the organisation of dorsocentral setae $(1+2$ for $H$. consobrina, $0+3$ for the remainder of the species), but Papp (1979) admits position of the fore pair of dorsocentral setae on the transversal suture in all three species. The position of dorsocentral setae thus seems to be at least problematic. The current state of knowledge suggests that only $H$. consobrina is discernible from the latter two species.

It is reasonable to ask, if there are some other reliable characters to identify the females, and first of all, how to reliably recognise the species they belong to. Of course, the first assumption is that females are morphologically different. The preliminary inspection of females suggests that they are. One of the possible ways to decide the species is to analyse wing shape by geometric morphometrics: females should have more similar wing shape to their conspecific males, or more stringently, the wing shape should be non-significantly different between sexes of the same species.

During faunistical research in western Slovakia (Semelbauer \& Vidlička 2015), a considerable sample of $H$. patelliformis and $H$. thalhammeri was obtained. This opened the opportunity to analyze females by means of geometric morphometrics. H. consobrina, as a close relative of $H$. thalhammeri, was included as well. The main goal of the paper is to identify females of the three species and describe their terminalia in detail.

\section{Material and methods}

\section{Material collection}

All of the specimens come from the private collections of the author and Milan Kozánek were obtained either via Malaise trap or by sweep netting. The specimens were mounted on paper strips (altogether 143 females). Once prepared, the specimens were determined using the keys of Papp (1979) and Shatalkin (2000) using the English translation (Schacht et al. 2004). The original description of H. thalhammeri by Papp (1978) was studied as well. Females were inspected for their terminalia and divided in two groups: supposed H. thalhammeri and supposed H. patelliformis. The decision was based on intuition, but appears as a lucky guess; 24 females from each group were chosen. 24 males of $H$. patelliformis (Fig. 1) were added from the same locality (10 from 2015, 14 from 2016), but only 4 males of $H$. thalhammeri could be utilized from Šenkvice, consequently 6 males were added from two other localities. The material of $H$. consobrina was even more limited, summing only to 5 males and 7 (putative) females from two localities. In total, 94 specimens were included (Tab 1).

\section{Study sites}

Montenegro, Durmitor National Park, 10-13.VII 2001, lgt. Langourov; Slovakia, Šenkvice, GPS: 48 $18^{\prime} 11.16^{\prime \prime N}, 17^{\circ} 21^{\prime} 31.68^{\prime \prime E}$, 20.6.-12.8. 2015, lgt; Vidlička, Kozánek, Semelbauer, MT; Slovakia, Šenkvice, GPS: $48^{\circ} 18^{\prime} 05.69^{\prime \prime} \mathrm{N}, 1^{\circ} 21^{\prime} 38.80 " \mathrm{E}, 14.6 .-12.7$. 2016, lgt; Vidlička, MT; Slovakia, Nitrianske Rudno, GPS: $48^{\circ} 47^{\prime} 13.14^{\prime \prime N}, 18^{\circ} 27^{\prime} 8.16^{\prime \prime E}$, 3.5. 2008. lgt. Majzlan, MT; Slovakia, Muránska planina, Paseky, GPS: 48 $42^{\prime} 48.87^{\prime \prime}$, 1959'51.65", 29.6.-6.7. 2001, lgt. Vidlička, MT; Slovakia, Krasín, GPS: 4857'45.83"N, $18^{\circ} 00^{\prime} 23.71 " \mathrm{E}, 23.6-13.9 .2014$, lgt. Majzlan, MT.

\section{Collection of landmarks}

The wings were mechanically removed, immersed in alcohol, mounted on slides with glycerol and photographed in 16x magnification under Stemi 2000-C stereomicroscope with a mounted Micrometrics SE camera. Each image was labelled so that the first three characters correspond with the unique specimen number, the fourth one to the locality, the fifth one to the (in females supposed) species and the last one to the sex. A tps file was created from the images using the tpsutil (Rholf 2010); the landmarks were digitized using tpsdig (Rohlf 2009). The position and order of landmarks is depicted in Fig. 2. 


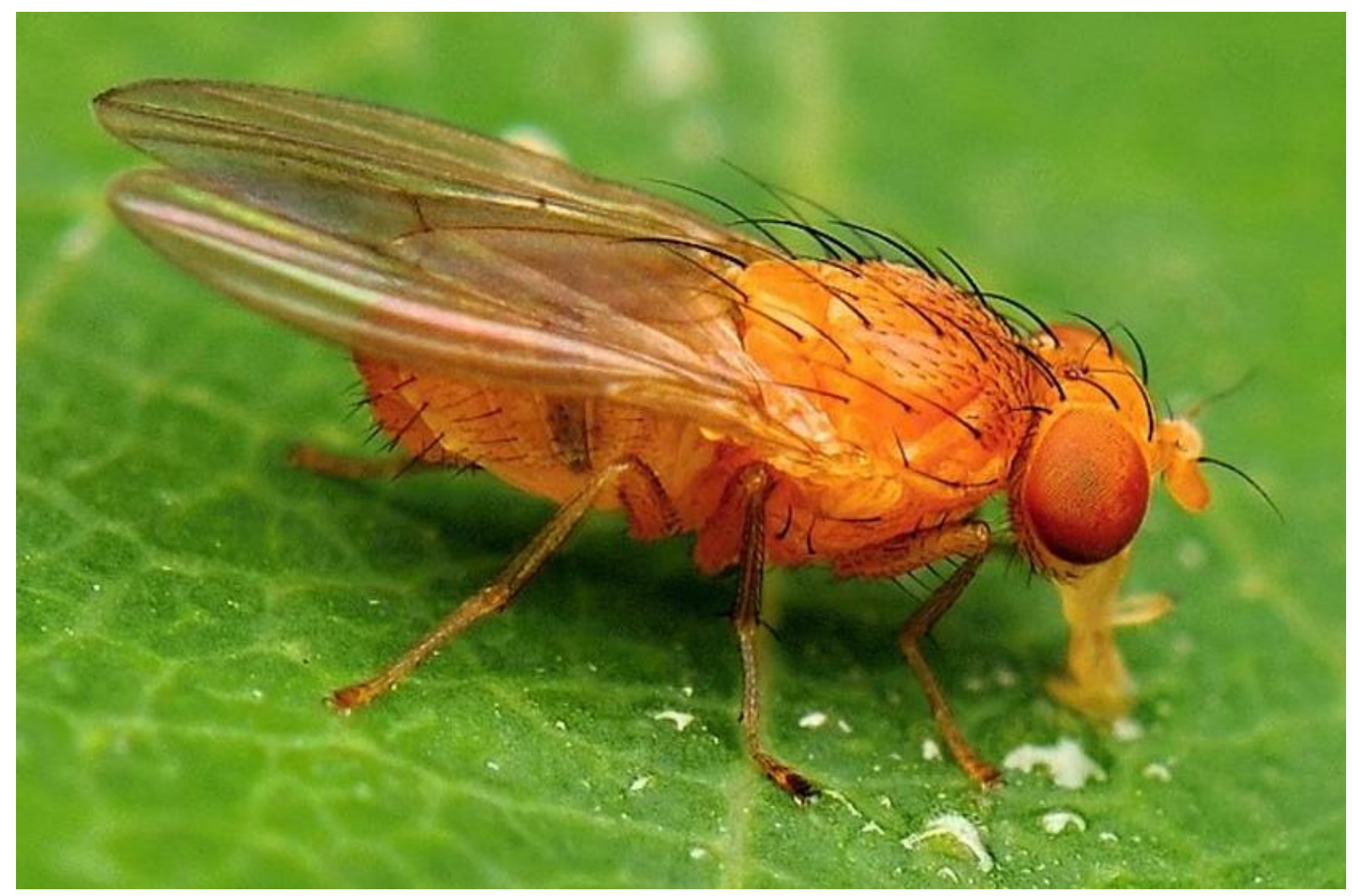

Fig 1: Male of Homoneura patelliformis. Photo by Milan Kozánek

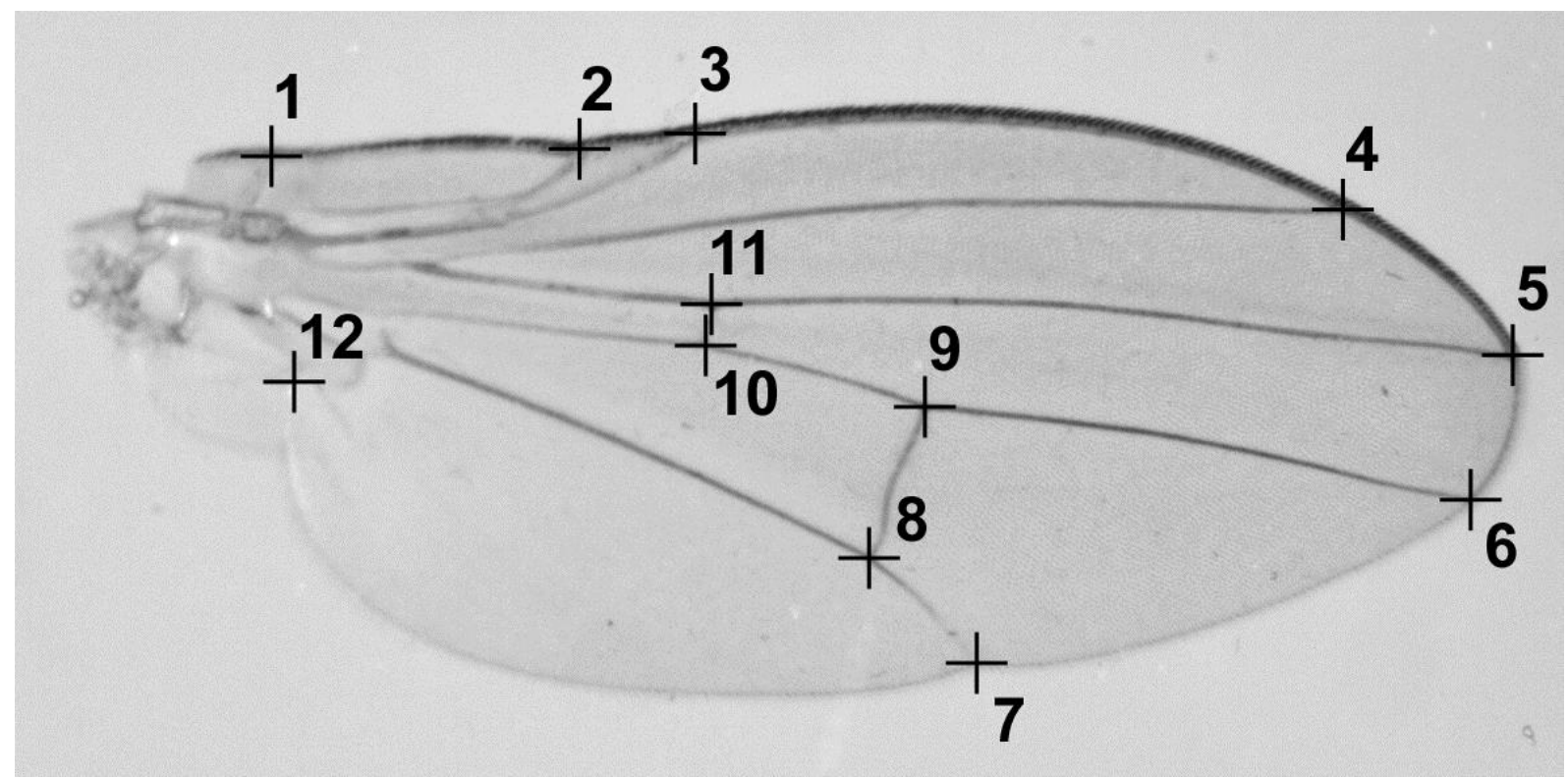

Fig 2: Homoneura patelliformis wing with marked position and order of landmarks. Most landmarks are localized on the cross-section of two veins. Only landmark 12 is localized on the 2 nd anal vein near the meeting point of the alula and the anal lobe. 


\section{Statistical analysis}

The raw coordinates were superimposed by the Generalized Procrustes Analysis (GPA), using the function gpagen from package geomorph (Adams \& Otárola-Castillo 2013) implemented in R (R Core Team, 2013). In the GPA, differences due to position, rotation and scale are filtered out. During the superimposition, four degrees of freedom are lost, which complicates computing the degrees of freedom in statistical tests. One possibility of coping with this problem is to use a principal component analysis (PCA) (Zelditch et al 2004). The last four principal components (PCs) of Procrustes coordinates have zero eigenvalues and can be omitted, i.e. 24-4 PCs were used for statistical tests. The reconstruction of the shape change along the principal components was performed by tpsrelw (Rholf 2008). More information on the GPA method can be found in Claude (2008, 2013), Webster \& Sheets (2010) and Viscosi \& Cardini (2011). The data manipulation and analysis was performed in R using functions available in the package geomorph (Adams \& Otárola-Castillo 2013) and Claude (2008, 2013).

Three files are provided as a supplement: lands.tps contains original landmark coordinates of both digitization sessions; factor.txt contains a table of factors with four variables: the ID (unique code for each specimen), species (3 levels), sex, and locality (5 levels); finally, R code.doc contains the source code for program R.

\section{Results}

\section{GM analysis of wings}

Measurement error (ME). To obtain the ME, the digitization of all specimens was repeated twice. A variance for the $\mathrm{x}$ and $\mathrm{y}$ coordinate was obtained for each landmark and specimen and then summed. For specimens where the variance was exceedingly large, the respective landmarks were visually inspected and adjusted in tps dig. Landmarks 2, 3, 4 and 12 appear as the least reliable, i.e. these landmarks were less clearly defined. To asses the ME, an ANOVA approach was applied, as described in Yezerinac et al. (1992) and adapted from Claude (2013). Two linear models were fitted to the data. In the first model, the explanatory variable was the individual factor (94 levels); in the second one it was the session factor (2 levels). Both for centroid size and shape variables (24-4 PCs obtained from the Procrustes coordinates) the individual factor was highly statistically significant (p-value $<0.0001$ ), while the session factor was not ( $\mathrm{p}$-value $>0.93$ ). The results suggest that the variability caused by measurement error is negligibly small and that most of the variability comes from interindividual differences. Once the ME was evaluated, the pseudoreplicates were averaged.

Centroid size. A linear model was fitted to the centroid size with species and sex as explanatory variables. Sex appears to be the only significant factor (Tab. 2), with the females being larger on average (Fig. 3).

Shape. A PCA was performed on the Procrustes coordinates (Fig. 4). The first two principal components explained $32 \%$ and $20 \%$ of the variance. 24-4 PCs were selected for subsequent analysis. To test the effects of explanatory variables (species, sex and size) for shape, a linear model was fitted to the data. All of the main effects and none of the interaction terms were significant (Tab. 3). A subsequent pairwise comparison reveals that $H$. patelliformis is significantly different from the latter two species, while $H$. thalhammeri and H. consobrina are not significantly different (Tab. 4)

To allow comparisons of putative females of $H$. patelliformis and $H$. thalhammeri to males, the original model was slightly adjusted. Explanatory variables sex and species were combined into single variable ,sexsp“ with 6 levels. As far as the sexes differ in centroid size, and the effect of size on shape was significant, it is possible that in comparison of opposite sexes, the result would be significant only because of the size effect of sex. Therefore, the effect of size was filtered out through multivariate regression (the interaction term was nonsignificant, suggesting that the change of shape with size can be considered the same for all species). In the model, residuals were used as explained variable, while the factor "sexsp" as explaining variable. As expected, the factor "sexsp" was significant (results not shown). In a pairwise comparison (only H. thalhammeri and H. patelliformis), intraspecific comparisons were not significant, while extraspecific comparisons were highly significant (Tab. 5). 


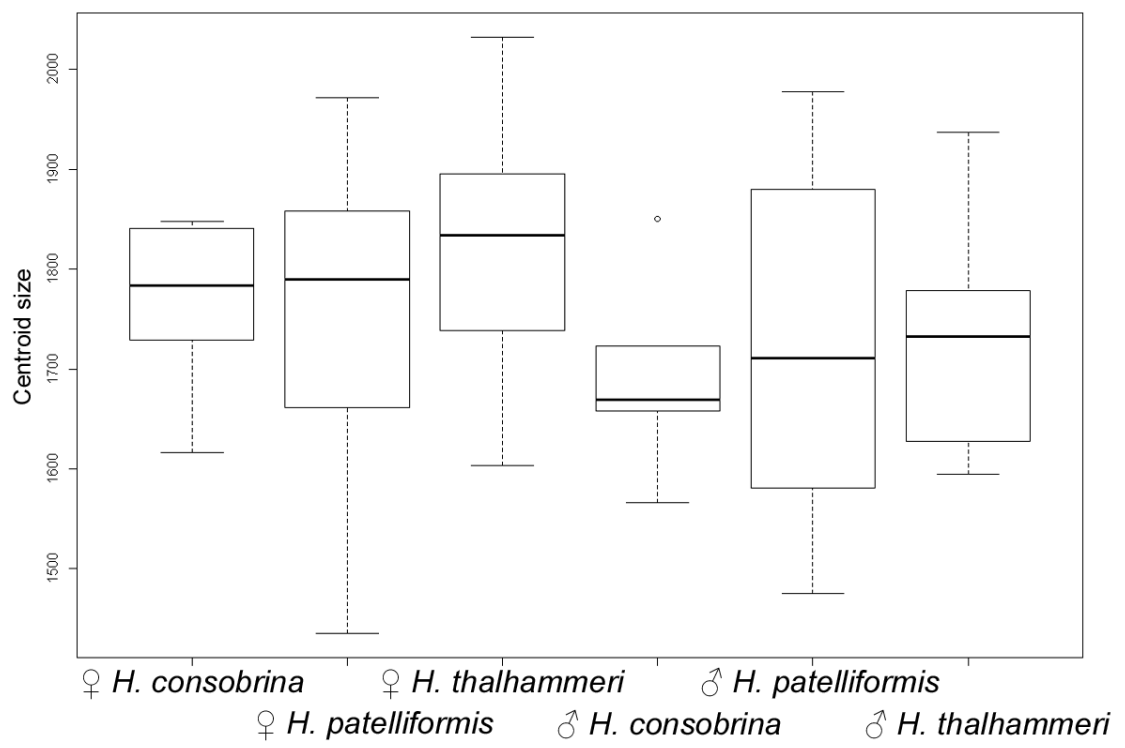

Fig 3: Boxplot of centroid sizes.

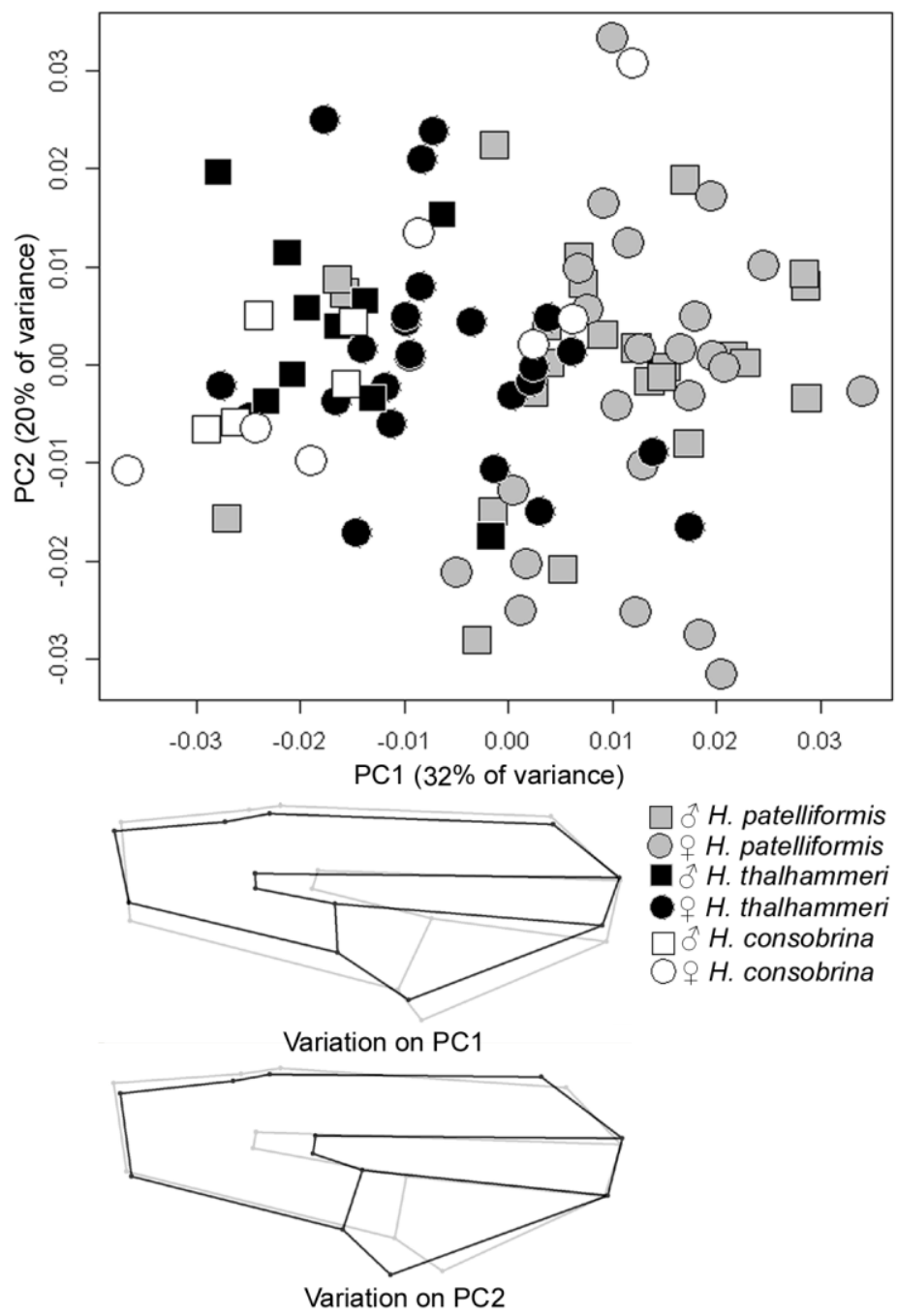

Fig 4: Principal component analysis (PCA) of Procrustes coordinates with depiction of shape change along the first two principal components. The magnitude of shape change was multiplied by factor 2 . 


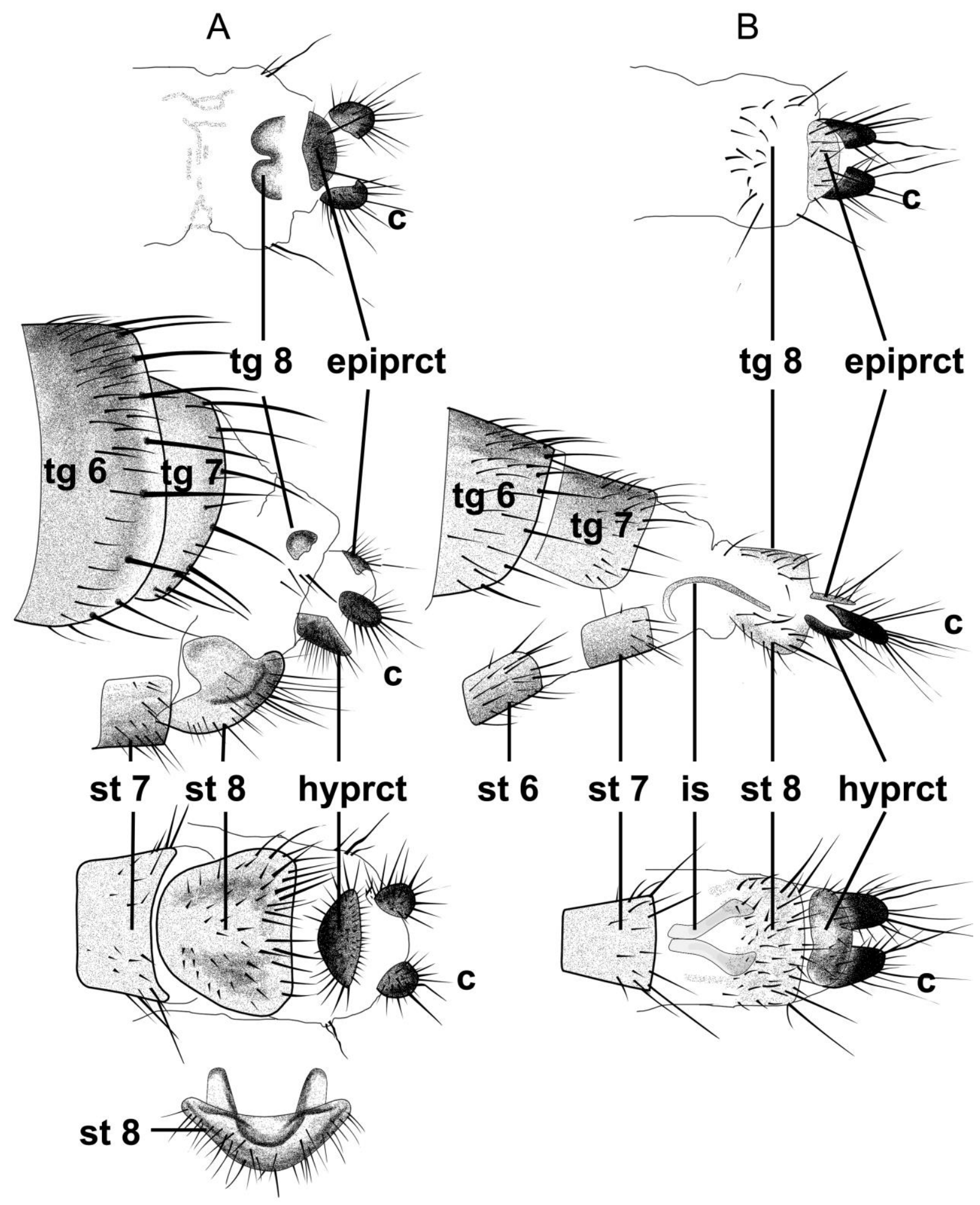

Fig 5: Female terminalia of Homoneura patelliformis (A) and H. thalhammeri (B). From the top: dorsal, lateral and ventral view, the most bottom st 8 depicts st 8 in posterior view. c - cercus; epiprct - epiproct; hyprct hypoproct; is - internal sclerites; st 6-st 8 -6th to 8th sternite; $\operatorname{tg} 6$-tg8 - 6th to 8th tergite. 
A linear discriminant analysis (LDA) was applied to the Procrustes coordinates to asses, how efficiently the wing shape is discriminating between the species. If all three species were considered, $82.3 \%$ of all specimens were correctly assigned. If $H$. consobrina was excluded, about $96 \%$ of all specimens were correctly assigned. On the other hand, if the identity of females was switched (and H. consobrina excluded), only about $57 \%$ of specimens were correctly assigned.

\section{Female terminalia}

Based on the result of the wing shape analysis, it is now possible to determine the species of female forms for $H$. patelliformis and $H$. thalhammeri. Both species differ profoundly in the structure of the terminalia, though both have $2+1$ spermathecae. $H$. patelliformis has an enlarged and convex 8th sternite, internally with two high longitudinal crests; the possible 8th tergite has a peculiar shape and is probably permanently retracted; epiproct, hypoproct and cerci are dark brown (Fig. 5A). H. thalhammeri has both the 8th tergite and sternite reduced and weakly sclerotised; the sclerites of the 8th segment are adjoined to the 7th segment by a long retractable membrane, probably everted during copulation and/or oviposition; the inside of the everted membranous part a pair of fine elongated sclerites is visible, which probably reinforce the membranous part when everted. The cerci and hypoproct are dark brown; the epiproct is weakly sclerotised and yellowish. The cerci are elongated compared to H. patelliformis (Fig. 5B).

Table 1: Numbers of specimens used in the present study.

\begin{tabular}{|c|c|c|c|c|c|c|}
\hline Species/locality & Krasín & Montenegro & Paseky & Rokoš & Šenkvice & totally \\
\hline H. consobrina & $5 q, 4{ }^{\lambda}$ & - & $2+, 1 \sigma^{\lambda}$ & - & - & 12 \\
\hline H. patelliformis & 1. & - & 1 & - & $24 ㅇ, 24 \hat{\jmath}$ & 48 \\
\hline H. thalhammeri & - & $4{ }^{\lambda}$ & - & $2 \widehat{\sigma}$ & $24+4{ }^{\lambda}$ & 35 \\
\hline totally & 11 & 4 & 3 & 2 & 76 & 94 \\
\hline
\end{tabular}

Table 2: Results of ANOVA on centroid size, type II SS.

\begin{tabular}{lcccl}
\hline & Sum Sq & Df & F value & p-value \\
\hline species & 27975 & 2 & 0.8338 & 0.43781 \\
sex & 75462 & 1 & 4.4982 & $0.03674 *$ \\
species:sex & 14484 & 2 & 0.4317 & 0.65077 \\
Residuals & 1476282 & 88 & & \\
\hline
\end{tabular}

Table 3: Results of MANOVA performed on first 20 principal components.

\begin{tabular}{lcccccl}
\hline & Df & Pillai & approx F & num Df & den Df & p-value \\
\hline species & 2 & 1.20703 & 4.8710 & 40 & 128 & $4.150 \mathrm{e}-12 * * *$ \\
sex & 1 & 0.41758 & 2.2585 & 20 & 63 & $0.007521 * *$ \\
size & 1 & 0.61601 & 5.0532 & 20 & 63 & $3.832 \mathrm{e}-07 * * *$ \\
species:sex & 2 & 0.37576 & 0.7403 & 40 & 128 & 0.862938 \\
species:size & 2 & 0.54623 & 1.2024 & 40 & 128 & 0.219752 \\
sex:size & 1 & 0.24664 & 1.0313 & 20 & 63 & 0.441398 \\
species:sex:size & 2 & 0.45942 & 0.9543 & 40 & 128 & 0.554273 \\
Residuals & 82 & & & & & \\
\hline
\end{tabular}


Table 4: Pairwise comparison between species.

\begin{tabular}{lcccccl}
\hline & Df & Pillai & Approx F & num Df & den Df & p-value \\
\hline H. patelliformis: H. thalhammeri & 1 & 0.84810 & 16.4704 & 20 & 59 & $<2.2 \mathrm{e}-16 * * *$ \\
H. patelliformis: H. consobrina & 1 & 0.85584 & 10.9833 & 20 & 37 & $4.175 \mathrm{e}-10 * * *$ \\
H. thalhammeri: H. consobrina & 1 & 0.48812 & 1.09662 & 20 & 23 & 0.41248 \\
\hline
\end{tabular}

Table 5: Pairwise comparison within and between species after correction for size.

\begin{tabular}{|c|c|c|c|c|c|c|}
\hline & Df & Pillai & Approx F & num Df & den Df & p-value \\
\hline$\widehat{\widehat{O} H .}$ patelliformis: $\hat{\delta} \mathrm{H}$. thalhammeri & 1 & 0.8793 & 4.7352 & 20 & 13 & $0.003066 * *$ \\
\hline$\hat{\mathrm{O} H}$. patelliformis: + $H$. thalhammeri & 1 & 0.8357 & 6.8682 & 20 & 27 & $3.714 \mathrm{e}-06 * * *$ \\
\hline O H. patelliformis: $\bigcirc$ H. thalhammeri & 1 & 0.92106 & 15.75 & 20 & 27 & $4.186 \mathrm{e}-10 * * *$ \\
\hline O H. patelliformis: ${ }^{2} H$. thalhammeri & 1 & 0.88209 & 4.863 & 20 & 13 & $0.002697 * *$ \\
\hline$\hat{\mathrm{O}}$ H. patelliformis: $ᄋ$ H. patelliformis & 1 & 0.55969 & 1.72 & 20 & 27 & 0.09496 \\
\hline O H. thalhammeri: 0 H. thalhammeri & 1 & 0.69434 & 1.477 & 20 & 13 & 0.2378 \\
\hline
\end{tabular}

\section{Discussion}

\section{Homoneura patelliformis and $H$. thalhammeri}

According to the morphology of terminalia, females can be easily and reliably recognised. At the same time, wing shape clearly determines the species. Not only is the wing shape significantly different among the species, but almost all (96\%) of the specimens are correctly assigned by the linear discriminant function. The best characteristics to discern females without dissection is the enlarged convex 8th sternite and dark brown epiproct for $H$. patelliformis and much reduced 8th sternite and pale epiproct for $H$. thalhammeri. This finding is in agreement with Carles-Tolrá (1993), where the shape of the 8th sternite of $H$. ericpoli is similar to that of $H$. patelliformis. Both species are, according to the male terminalia, closely related. The role of peculiar 8th tergite remains to be clarified by future research. It might be interesting to ask, if females of $H$. patelliformis, H. ericpoli and H. chelis somehow differ in terminalia. The species co-occur in the Iberian Peninsula and in faunistical research it might be useful information.

\section{H. thalhammeri and H. consobrina}

The species do not significantly differ in wing shape. This can be attributed to several factors. The most obvious is a low number of specimens $(12 \mathrm{H}$. consobrina vs. $35 \mathrm{H}$. thalhammeri). The species are likely very closely related, i.e. too little time has passed to accumulate enough morphological change to be detectable by the GM. And finely, no clear morphological difference in terminalia between females of assumed $H$. consobrina and $H$. thalhammeri was found. The females were assumed to be $H$. consobrina, based on the evidence that they co-occur with male $H$. consobrina and that no $H$. thalhammeri male was found on the localities. Therefore, it is possible that some or all of the females were erroneously considered as $H$. consobrina. To identify morphological differences between females, if there are any, requires the sample size considerably extended and more rigorously tested for differences e.g. in shape of terminalia sclerites, not only a visual inspection.

Species identification as revealed by the GM analysis is not consistent with Papp (1979), who states that females of $H$. consobrina have the short 7 th sternit sparsely covered in setae, while the female $H$. patelliformis and $H$. thalhammeri should have a long 7 th sternit densely covered in long setae. A possible explanation is that Papp (1979) mistakenly considered the 8th sternit of $H$. patelliformis as 7th sternit (the 8th tergite is not visible and 7th tergite visually opposes the 8th tergite) and considered females of $H$. patelliformis as females of $H$. thalhammeri. 


\section{Conclusion}

It could be argued that the identification of females via geometric morphometrics was excessively laborious (preparation of slides, photographing and double digitization of 94 specimens took about two days) and that females can be associated with species simply based on male counts, so that the more numerous female form will be identified with the more numerous male. Now, with the knowledge of the female identity, the whole set of 143 prepared females from Šenkvice 2015 can be evaluated. The counts of males and females are as follows: $H$. thalhammeri: $6 \hat{\jmath}, 969, H$. patelliformis: $16 \hat{\jmath}, 47+$. As it happens, the females of the „rare" $H$. thalhammeri are twice as common as $H$. patelliformis females, while the opposite applies to the males.

Note, that $H$. thalhammeri switched from ,rare“ species, occurring in few specimens to almost dominant lauxaniid (only 3 common species being more numerous in Šenkvice, see Semelbauer \& Vidlička 2015). The rare occurrence is likely the result of a strongly female biased sex ratio, as have e.g. Phengaris butterflies (Nowicki et al. 2005), though in the case of Malaise trap samples this can be explained also by female biased dispersal activity.

In superficially similar and sympatric species, the GM proves to be a powerful, quick and cheap method to identify females. The method requires substantial number of specimens, what can pose serious limitation in rare species, such as the $H$. consobrina. A possibility remains open that many more species within lauxaniids have females with specific terminalia, but remain unnoticed. Insufficient knowledge of females is restrictive in faunistical research and thereafter in evaluating the conservation status of many insect species.

Aknowledgments: The research was supported by the grant APVV-14-0652 „Pesticide-free control of the house fly and stable fly populations on livestock farms in Slovakia ". The author also sends his thanks to Milan Kozánek for providing the photography of Homoneura patelliformis and to Lubomír Vidlička for help with the malaise traps.

\section{References}

Adams D.C. \& Otárola-Castillo E. (2013): geomorph: an R package for the collection and analysis of geometric morphometric shape data. - Methods in Ecology and Evolution 4(4): 393-399.

Claude J. (2008): Morphometrics with R. Springer Science \& Business Media, LLC, 317 pp.

- (2013): Log-shape ratios, Procrustes superimposition, elliptic Fourier analysis: three worked examples in R. Hystrix, the Italian Journal of Mammalogy 24(1): 94-102.

Carles-Tolrá M. (1993): Homoneura ericpoli and Sapromyza (Sapromyzosoma) cabrilsensis: two new species from Spain (Diptera, Lauxaniidae). - Zoologica Baetica 4: 25-30.

- (1996): Homoneura chelis spec. nov., a new lauxaniid species from Spain (Insecta: Diptera: Lauxaniidae). Staatliches Museum für Tierkunde Dresden 31(41): 229-231.

Merz B. (2002): Einführung in die Familie Lauxaniidae (Diptera, Acalyptrata) mit Angaben zur Fauna der Schweitz. - Mitteilungen der Entomologischen Gesellschaft Basel 52 (2-3): 29-128.

Nowicki P., Witek M., Skorka P., Settele J. \& Woyciechowski M. (2005): Population ecology of the endangered butterflies Maculinea teleius and M. nausithous and the implications for conservation. Population Ecology 47(3): 193-202.

Papp L. (1978): Contribution to the revision of the Palearctic Lauxaniidae (Diptera). - Annales HistoricoNaturales Musei Nationalis Hungarici 70: 213-231.

- (1979): 57 abrával. Korhádéklegyek-Pajzstetűlegyek. Lauxaniiade-Chamaemyiidae. - Fauna Hungariae 136: $1-59$.

R Core Team (2013): R: A language and environment for statistical computing. R Foundation for Statistical Computing, Vienna, Austria. http://www.R-project.org/ - accesed 12.2.2016.

Rohlf, F.J. (2008): 'Relative warps. Version 1.46.' Available at http://life.bio.sunysb.edu/morph/ - accesed 15.4.2016.

- (2009): 'TpsDig-thin plate spline digitizer. ' Version 2.14. Available at http://life.bio.sunysb.edu/morph/ accesed 15.4.2016.

- (2010): 'tps Utility program.' Version 1.47. Available at http://life.bio.sunysb.edu/morph/ - accesed 15.4.2016.

Schacht W., Kurina O., Merz B. \& Gaimari S. (2004): Zweiflüger aus Bayern XXIII (Diptera: Lauxaniidae, 
Chamaemyidae). - Entomofauna, Zeitschrift für Entomologie 25(3): 41-80.

Semelbauer M. (2015): Neoparoecus simplicipes Yarom 1991 (Diptera, Lauxaniidae) and Homoneura consobrina (Zetterstedt 1847) new to Slovakia. - Entomofauna carpathica 27(1): 57-62.

- (2016): Molecular phylogeny of lauxaniid flies (Diptera, Cyclorrhapha) confirms non-monophyly of Sapromyza Fallén 1810. - Insect Systematics \& Evolution 47(4): 389-409.

Semelbauer M. \& Vidlička L'. (2015): Tieňovky (Diptera, Lauxaniidae) a siet'korídlovce (Neuroptera) v areáli PD Šenkvice (trnavaská pahorkatina). - Entomofauna carpathica 27(2): 1-9.

Shatalkin A.I. (2000): Opredelitel palearkticheskych much semejstva Lauxaniidae (Diptera). - Zoologicheskie Issledovania 5: 1-102.

Viscosi V. \& Cardini A. (2011): Leaf morphology, taxonomy and geometric morphometrics: A simplified protocol for beginners. - PLoS ONE 6(10): e25630.

Webster M. \& Sheets H.D. (2010): A practical introduction to landmark-based geometric morphometrics. In: Alroy J. \& Hunt G. (eds) Quantitative Methods in Paleobiology. Paleontological Society Short Course, The Paleontological Society Papers, Volume 16, pp. 163-188.

Yezerinac S.M., Loogheed S.C. \& Handford P. (1992): Measurement error and morphometric studies: statistical power and observer experience. - Systematic Biology 41(4): 471-482.

Zelditch M.L., Swiderski D.L., Sheets H.D. \& Fink W.L. (2004): Geometric Morphometrics for Biologists: A Primer. Elsevier/Academic Press, Amsterdam, 443 pp.

Author's address: Marek Se melbauer, Institute of Zoology, Slovak Academy of Sciences, Dúbravská cesta 9, 84506 Bratislava, Slovakia \& Prales, Odtrnovie 563, 01322 Rosina, Slovakia. E-mail: semelbauer.m@gmail.com

\section{Appendix 1. $R$ code}

\section{\#ANALYSIS OF Homoneura WINGS}

\#Loading packages

library(geomorph);library(car);library(MASS)

\section{\#Reading data}

lands <- readland.tps(file.choose())\#read file lands.tps, the raw coordinates of landmarks

factor<-read.table(file.choose(),header=TRUE);attach(factor) \#read the factor table (Appendix 2)

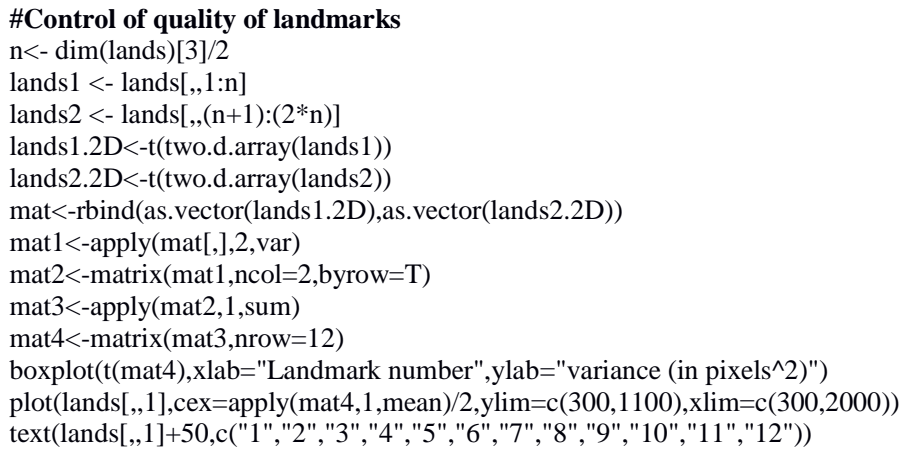

\#Meassurement error of centroid size session<-gl $(2, \mathrm{n})$

\#Measurement error of Procrustes coordinates pc $<$-princomp(lands.2d)

summary(manova(pc\$scores[,1:20] ind))

summary(manova(pc\$scores[,1:20] session)) 
\#Averaging the Procrustes coordinates; $n$-number of specimens; $\mathbf{c}$-number of coordinates

$\mathrm{n}<-\operatorname{dim}($ lands) [3]/2; $\mathrm{c}<-2 * \operatorname{dim}$ (lands)[1]

sess $1<$-gpa.lands \$coords[,,1:n]

sess $2<$-gpa.lands $\$$ coords $[,,(n+1):(2 * n)]$

me<-as.matrix(cbind(sess 1 ,sess 2$)$ )

mco<-apply(me, 1, mean $)$

$\mathrm{m}<-0:(\mathrm{n}-1)$

mgpa $<$-array $(\operatorname{dim}=c(12,2, \mathrm{n}))$

for (i in $1: n)\left\{\operatorname{mgpa}[,, \mathrm{i}]<-\operatorname{matrix}\left(\operatorname{mco}\left[\left(\mathrm{m}[\mathrm{i}]{ }^{*} \mathrm{c}+1\right):\left(\mathrm{i}^{*} \mathrm{c}\right)\right], \mathrm{nrow}=12\right)\right\}$

\# Averaging the size

msize<-apply(matrix(size,ncol=2), 1, mean)

\#ANOVA, centroid size

$\mathrm{m} 1<-\operatorname{lm}\left(\right.$ msize $\sim$ species* ${ }^{*}$ sex,type $\left.=2\right)$

Anova $(\mathrm{m} 1)$

\#model criticism

$\operatorname{par}(\mathrm{mfrow}=\mathrm{c}(2,2))$

$\operatorname{plot}(\mathrm{m} 1)$

shapiro.test $(\operatorname{resid}(\mathrm{m} 1))$

bartlett.test(msize sexsp)

\#Boxplot, centoid size

sexsp<-paste(sex,species)

boxplot(msize $\sim \operatorname{sexsp}, y l a b=$ "Centroid size" $)$

\#PCA

pc<-princomp(mgpa)

summary $(\mathrm{pc})$

\#PCA plot

$\operatorname{par}(\mathrm{mfrow}=\mathrm{c}(1,1))$

plot(pc\$scores[,c(1,2)],xlab="PC1 (32\% of variance)",ylab="PC2 (20\% of

variance)",cex=3,pch=c(21,22)[sex],bg=c("white","grey","black")[species], col=c("black","black","white")[species])

legend(locator(1),c("m patelliformis","f patelliformis","m thalhammeri","f thalhammeri","m consobrina","f

consobrina"),pch=c(22,21,15,16,22,21)

\#MANOVA

shv<-pc\$scores[,1:20]

summary(manova(shv species*sex*msize)

\#Pair-wise comparison between species

summary(manova(shv species*msize,subset=species\%in\%c("patelliformis","thalhammeri")))

summary(manova(shv species*msize,subset=species\%in\%c("patelliformis","consobrina")))

summary(manova(shv $\sim$ species*msize,subset=species\%in\%c("consobrina","thalhammeri")))

\#MANOVA adjusted to compare sexes within and between species

\#Filtering out the effect of size

res<-resid(lm(shv msize $)$ )

\#Adjusted linear model

summary(manova(res sexsp))

\#Pairwise comparison between species

summary(manova(res $\sim$ sexsp,subset=sexsp\%in\%c("male patelliformis","male thalhammeri")))

summary(manova(res sexsp,subset=sexsp\%in\%c("male patelliformis","female thalhammeri")))

summary(manova(res sexsp,subset=sexsp\%in\%c("female patelliformis","female thalhammeri"))

summary(manova(res sexsp,subset=sexsp\%in\%c("female patelliformis","male thalhammeri")))

\# Pairwise comparison within species

summary(manova(res sexsp,subset=sexsp\%in\%c("male patelliformis","female patelliformis")))

summary (manova(res sexsp,subset=sexsp\%in\%c("male thalhammeri","female thalhammeri"))

\#Linear discriminant analysis (LDA)

ldafit<-lda(mgpa,species, CV=T)

length(which(ldafit\$class==species))/length(species)

\#LDA with $H$. patelliformis and $H$. thalhammeri only.

species2<-species[species!="consobrina"]

mgpa2<-mgpa[species!="consobrina",]

ldafit<-lda(mgpa2,species2,CV=T)

length(which(ldafit\$class==species2))/length(species2)

\#Same as previous, females with switched identity

species $3<-$ as.factor(sexsp)

levels(species3) $[\mathrm{c}(1,4)]<-$ "consobrina"

levels(species3)[2]<-"thalhammeri"

levels(species3)[3]<-"patelliformis"

levels(species3)[4]<-"patelliformis"

levels(species3)[4]<-"thalhammeri"

species4<-species3[species3!="consobrina"]

ldafit<-lda(mgpa2,species4,CV=T)

length (which(ldafit\$class==species4))/length( $\operatorname{species} 4)$ 


\section{Appendix 2. Table of factors required by the $\mathbf{R}$ code}

\begin{tabular}{|c|c|c|c|c|c|c|c|}
\hline ID & locality & species & sex & ID & locality & species & sex \\
\hline $001 \mathrm{spm}$ & Senkvice & patelliformis & male & $048 \mathrm{spf}$ & Senkvice & patelliformis & female \\
\hline $002 \mathrm{spm}$ & Senkvice & patelliformis & male & 049stf & Senkvice & thalhammeri & female \\
\hline 003spm & Senkvice & patelliformis & male & 050stf & Senkvice & thalhammeri & female \\
\hline 004spm & Senkvice & patelliformis & male & 051stf & Senkvice & thalhammeri & female \\
\hline $005 \mathrm{spm}$ & Senkvice & patelliformis & male & 052stf & Senkvice & thalhammeri & female \\
\hline $006 \mathrm{spm}$ & Senkvice & patelliformis & male & 053stf & Senkvice & thalhammeri & female \\
\hline 007spm & Senkvice & patelliformis & male & 054stf & Senkvice & thalhammeri & female \\
\hline 008spm & Senkvice & patelliformis & male & $055 \mathrm{stf}$ & Senkvice & thalhammeri & female \\
\hline 009spm & Senkvice & patelliformis & male & 056stf & Senkvice & thalhammeri & female \\
\hline 010spm & Senkvice & patelliformis & male & 057stf & Senkvice & thalhammeri & female \\
\hline 011spm & Senkvice & patelliformis & male & 058stf & Senkvice & thalhammeri & female \\
\hline $012 \mathrm{spm}$ & Senkvice & patelliformis & male & 059stf & Senkvice & thalhammeri & female \\
\hline $013 \mathrm{spm}$ & Senkvice & patelliformis & male & 060stf & Senkvice & thalhammeri & female \\
\hline 014 spm & Senkvice & patelliformis & male & 061stf & Senkvice & thalhammeri & female \\
\hline $015 \mathrm{spm}$ & Senkvice & patelliformis & male & 062stf & Senkvice & thalhammeri & female \\
\hline 016 spm & Senkvice & patelliformis & male & 063stf & Senkvice & thalhammeri & female \\
\hline $017 \mathrm{spm}$ & Senkvice & patelliformis & male & 064stf & Senkvice & thalhammeri & female \\
\hline 018 spm & Senkvice & patelliformis & male & $065 \mathrm{stf}$ & Senkvice & thalhammeri & female \\
\hline $019 \mathrm{spm}$ & Senkvice & patelliformis & male & 066stf & Senkvice & thalhammeri & female \\
\hline 020spm & Senkvice & patelliformis & male & 067stf & Senkvice & thalhammeri & female \\
\hline $021 \mathrm{spm}$ & Senkvice & patelliformis & male & 068stf & Senkvice & thalhammeri & female \\
\hline 022spm & Senkvice & patelliformis & male & 069stf & Senkvice & thalhammeri & female \\
\hline 023spm & Senkvice & patelliformis & male & 070stf & Senkvice & thalhammeri & female \\
\hline 024spm & Senkvice & patelliformis & male & 071stf & Senkvice & thalhammeri & female \\
\hline $025 \mathrm{spf}$ & Senkvice & patelliformis & female & 072stf & Senkvice & thalhammeri & female \\
\hline $026 \mathrm{spf}$ & Senkvice & patelliformis & female & $073 \mathrm{mtm}$ & Montenegro & thalhammeri & male \\
\hline $027 \mathrm{spf}$ & Senkvice & patelliformis & female & $074 \mathrm{mtm}$ & Montenegro & thalhammeri & male \\
\hline $028 \mathrm{spf}$ & Senkvice & patelliformis & female & $075 \mathrm{mtm}$ & Montenegro & thalhammeri & male \\
\hline $029 \mathrm{spf}$ & Senkvice & patelliformis & female & $076 \mathrm{mtm}$ & Montenegro & thalhammeri & male \\
\hline 030spf & Senkvice & patelliformis & female & 077stm & Senkvice & thalhammeri & male \\
\hline $031 \mathrm{spf}$ & Senkvice & patelliformis & female & 078stm & Senkvice & thalhammeri & male \\
\hline $032 \mathrm{spf}$ & Senkvice & patelliformis & female & 079stm & Senkvice & thalhammeri & male \\
\hline $033 \mathrm{spf}$ & Senkvice & patelliformis & female & 080stm & Senkvice & thalhammeri & male \\
\hline $034 \mathrm{spf}$ & Senkvice & patelliformis & female & 081ntm & Rokos & thalhammeri & male \\
\hline $035 \mathrm{spf}$ & Senkvice & patelliformis & female & 082ntm & Rokos & thalhammeri & male \\
\hline $036 \mathrm{spf}$ & Senkvice & patelliformis & female & $083 \mathrm{pcm}$ & Paseky & consobrina & male \\
\hline 037spf & Senkvice & patelliformis & female & $084 \mathrm{kcm}$ & Krasin & consobrina & male \\
\hline $038 \mathrm{spf}$ & Senkvice & patelliformis & female & $085 \mathrm{kcm}$ & Krasin & consobrina & male \\
\hline 039spf & Senkvice & patelliformis & female & $086 \mathrm{kcm}$ & Krasin & consobrina & male \\
\hline 040spf & Senkvice & patelliformis & female & $087 \mathrm{kcm}$ & Krasin & consobrina & male \\
\hline $041 \mathrm{spf}$ & Senkvice & patelliformis & female & 088pcf & Paseky & consobrina & female \\
\hline 042spf & Senkvice & patelliformis & female & 089pcf & Paseky & consobrina & female \\
\hline $043 \mathrm{spf}$ & Senkvice & patelliformis & female & 091kcf & Krasin & consobrina & female \\
\hline $044 \mathrm{spf}$ & Senkvice & patelliformis & female & $092 \mathrm{kcf}$ & Krasin & consobrina & female \\
\hline $045 \mathrm{spf}$ & Senkvice & patelliformis & female & 093kcf & Krasin & consobrina & female \\
\hline $046 \mathrm{spf}$ & Senkvice & patelliformis & female & $094 \mathrm{kcf}$ & Krasin & consobrina & female \\
\hline 047spf & Senkvice & patelliformis & female & $095 \mathrm{kcf}$ & Krasin & consobrina & female \\
\hline
\end{tabular}

